\title{
Genome-wide DNA methylation profile analysis identifies differentially methylated loci associated with ankylosis spondylitis
}

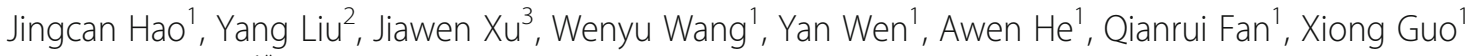
and Feng Zhang ${ }^{1 *}$

\begin{abstract}
Background: Ankylosing spondylitis (AS) is a chronic rheumatic and autoimmune disease. Little is known about the potential role of DNA methylation in the pathogenesis of AS. This study was undertaken to explore the potential role of DNA methylation in the genetic mechanism of AS.

Methods: In this study, we compared the genome-wide DNA methylation profiles of peripheral blood mononuclear cells (PBMCs) between five AS patients and five healthy subjects, using the Illumina Infinium HumanMethylation450 BeadChip. Quantitative real-time reverse transcription-polymerase chain reaction (qRT-PCR) was performed to validate the relevance of the identified differentially methylated genes for AS, using another independent sample of five AS patients and five healthy subjects.

Results: Compared with healthy controls, we detected 1915 differentially methylated CpG sites mapped to 1214 genes. The HLA-DQB1 gene achieved the most significant signal (cg14323910, adjusted $P=1.84 \times 10^{-6}, \beta$ difference $=0.5634$ ) for AS. Additionally, the CpG site cg04777551 of HLA-DQB1 presented a suggestive association with AS (adjusted $P=1.46 \times 10^{-3}, \beta$ difference $=0.3594$ ). qRT-PCR observed that the mRNA expression level of HLA-DQB1 in AS PBMCs was significantly lower than that in healthy control PBMCs (ratio $=0.48 \pm 0.10, P<0.001$ ). Gene Ontology (GO) and KEGG pathway enrichment analysis of differentially methylated genes identified four GO terms and 10 pathways for AS, functionally related to antigen dynamics and function.
\end{abstract}

Conclusions: Our results demonstrated the altered DNA methylation profile of AS and implicated HLA-DQB1 in the development of AS.

Keywords: Ankylosing spondylitis, Methylation, HLA-DQB1

\section{Background}

Ankylosing spondylitis (AS) is a chronic rheumatic and autoimmune disease, mainly damaging the axial skeleton, spine, and sacroiliac joints [1]. AS leads to the imbalance between bone resorption and bone formation, ultimately resulting in ligamentous ossifications and vertebral joint fusion [2]. AS usually starts before 30 years of age, manifested as chronic pain and stiffness of the low back. With age, loss of spinal mobility and chest expansion, extension of the

\footnotetext{
* Correspondence: fzhxjtu@xjtu.edu.cn

${ }^{1}$ Key Laboratory of Trace Elements and Endemc Diseases of National Health and Family Planning Commission, School of Public Health, Health Science Center, Xi'an Jiaotong University, Xi'an, People's Republic of China Full list of author information is available at the end of the article
}

lumbar spine becomes evident [3, 4], resulting in severe disability in AS patients [1]. It was reported that AS affects between 0.5 and 14 per 100,000 people every year [5].

Previous studies have demonstrated that AS is an inheritable disease with over $90 \%$ of AS risk determined by genetic factors [6]. HLA-B27 is a well-known susceptibility gene of AS. Approximately 95\% of AS patients express the HLA-B27 genotype [7-9]. However, less than 5\% of HLA-B27-positive individuals develop AS. Twin and family studies have suggested that HLAB27 accounts for less than $40 \%$ of the overall risk of AS [7-9]. In addition, tumor necrosis factor was implicated in the genetic mechanism of AS with limited genetic effect [10]. The missing heritability of 
AS suggests unknown genetic factors that contribute to the development of AS.

DNA methylation is an important epigenetic mechanism, playing an important role in gene expression regulation [11-13]. Extensive studies have demonstrated dysfunction of methylation in the development of multiple rheumatic and autoimmune diseases [14, 15]. Genome-wide DNA methylation profile comparative studies are a powerful tool for interrogating methylation changes associated with disease status. However, to the best of our knowledge, although some studies of abnormal methylated loci in AS patients have been conducted [16, 17], no genome-wide DNA methylation profiling of AS has so far been conducted. Little is known about the potential role of DNA methylation in the genetic mechanism of AS, limiting our efforts to clarify the pathogenesis and develop effective treatments for AS.

In this study, we first performed a genome-wide DNA methylation profile comparative analysis of peripheral blood mononuclear cells (PBMCs) between five AS patients and five healthy controls. Quantitative real-time reverse transcription-polymerase chain reaction (qRTPCR) was then conducted to validate the relevance of the identified differentially methylated genes with AS using another independent sample of five AS patients and five healthy controls.

\section{Methods}

\section{Human subjects}

Genetically unrelated male AS patients were recruited randomly from Xi'an 451 Hospital, Xi'an No.5 Hospital, and the Second Affiliated Hospital of Xi'an Jiaotong University in Xi'an city of Shaanxi province in China. All AS patients were diagnosed clinically and radiologically according to the modified New York criteria [18] by two AS experts. Specific for this study, 10 AS patients with bilateral grade 4 sacroiliitis and syndesmophytes were selected randomly from the recruited AS patients and used for genome-wide DNA methylation profile analysis and the qRT-PCR validation experiment, respectively (Table 1 and Fig. 1). Ten age-matched healthy males were recruited from Xi'an city as healthy control samples (Table 1). Clinical data for each participant were recorded by nurse-administered questionnaire, including self-reported ethnicity, lifestyle characteristics, health status, and family and medical histories. All study subjects are Chinese Han people. All patients were receiving only NSAIDs in the previous 3 months. Subjects with genetic bone diseases, cartilage diseases, rheumatic and autoimmune diseases, and undergoing biologic treatments were excluded from this study.
Table 1 Basic characteristics of the study subjects

\begin{tabular}{|c|c|c|c|c|}
\hline \multirow[t]{2}{*}{ Group } & \multicolumn{2}{|c|}{ Ankylosing spondylitis } & \multicolumn{2}{|c|}{ Healthy controls } \\
\hline & Age (years) & Gender & Age (years) & Gender \\
\hline \multicolumn{5}{|c|}{ Methylation chip } \\
\hline 1 & 22 & Male & 23 & Male \\
\hline 2 & 25 & Male & 23 & Male \\
\hline 3 & 27 & Male & 25 & Male \\
\hline 4 & 31 & Male & 30 & Male \\
\hline 5 & 31 & Male & 34 & Male \\
\hline \multicolumn{5}{|c|}{ qRT-PCR } \\
\hline 1 & 42 & Male & 32 & Male \\
\hline 2 & 28 & Male & 29 & Male \\
\hline 3 & 30 & Male & 32 & Male \\
\hline 4 & 30 & Male & 31 & Male \\
\hline 5 & 27 & Male & 25 & Male \\
\hline
\end{tabular}

QRT-PCR quantitative real-time reverse transcription-polymerase chain reaction

Monocyte derivation, DNA extraction, and quality control Five milliliters of peripheral blood was drawn from each participant. Following the manufacturer's recommended procedure, blood specimens were diluted with phosphate-buffered saline (PBS), laid with Lymphocyte Separation Medium (TBD Sciences), and centrifuged under $2500 \mathrm{rpm} / \mathrm{min}$ for $15 \mathrm{~min}$ to separate PBMCs. DNA was extracted from PBMCs using the TIANamp Blood DNA Kit (TIGEN Inc., China). The quality and concentration of extracted DNA were determined by NanoDrop ND-1000 Spectrophotometer (Thermo Fisher Scientific Inc., USA). The DNA specimens with A260/280 values varying from 1.8 to 2.0 were used in this study.

\section{Genome-wide DNA methylation profiling}

Genome-wide DNA methylation profiling of PBMCs was conducted using the Illumina Infinium HumanMethylation450 BeadChip according to the manufacturer's standard procedure. Briefly, bisulfite treatment of 500 ng DNA specimens was performed by the EZ DNA Methylation Kit (Zymo Research, USA). The bisulfiteconverted DNA specimens were then amplified, hybridized to a HumanMethylation450 array, stained, and washed. The raw image intensities of the hybridized arrays were scanned using an iScan SQ scanner (iScan System; Illumina). The obtained raw image intensity data were processed by GenomeStudio software (Illumina). The percentage of methylated cytosine at a given $\mathrm{CpG}$ locus was expressed as a $\beta$ value, varying from 0 (completely unmethylated) to 1 (completely methylated).

\section{Statistical analysis}

The correlations of study samples were first evaluated by calculating the Pearson correlation coefficients of $\beta$ 


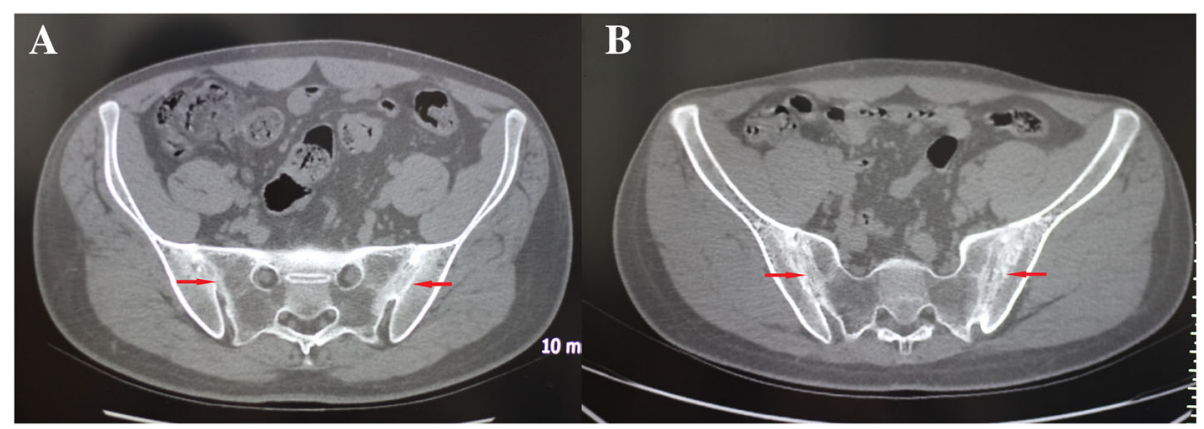

Fig. 1 Radiograph of two representative ankylosis spondylitis patients with bilateral grade 4 sacroilitis: a male, 28 years old; b male, 25 years old

values. The Empirical Bayes moderated $t$ test of the limma package from Bioconductor was used to compare the methylation profile difference between the AS group and the healthy control group. The Benjamini-Hochberg method was used to obtain an adjusted $P$ value for each CpG locus. For quality control, the CpG sites with missing values or detection $P>0.05$ in more than $90 \%$ of specimens were eliminated. The CpG sites with both adjusted $P<0.05$ and $\mid \beta$ difference $\mid>0.20$ were identified as significantly differentially methylated loci.

\section{Gene Ontology and pathway enrichment analysis}

Gene Ontology (GO) and pathway enrichment analysis were conducted by DAVID (http://david.abcc.ncifcrf.gov/) with all genes and pathways available on the Illumina Infinium HumanMethylation450 platform as the background to identify the cellular processes and canonical pathways that were enriched in the identified differentially methylated genes. Molecular function (MF), cellular component (CC), and biologic process (BP) were considered for GO enrichment analysis. For pathway enrichment analysis, we employed all 192 KEGG (http://www.genome.jp/kegg/) biopathways in this study. The GO terms and pathways were considered significantly enriched with FDR-adjusted $P<0.05$.

\section{qRT-PCR validation}

qRT-PCR was conducted to validate the relevance of identified differentially methylated genes for AS using an independent sample (Table 1). Total RNA was isolated from PBMCs using the TRIZOL kit (Invitrogen 15596026). The quality and purity of the isolated total RNA were examined by NanoDrop ND-1000 Spectrophotometer (Thermo Fisher Scientific Inc.). A total of $100 \mathrm{ng}$ of RNA was reverse-transcribed to complementary DNA (cDNA) using TaKaRa PrimeScript ${ }^{\mathrm{m}} \mathrm{RT}$ Master Mix (Takara Bio Inc., Japan). The quality and concentration of cDNA were determined by NanoDrop ND-1000 Spectrophotometer (Thermo Fisher Scientific Inc.). The cDNA specimens with A260/280 values varying from 1.8 to 2.0 were used in this study. All primers were supplied by TaKaRa. The forward and reverse primers of $H L A$ DQB1 are 5'-GGTGGGCAGAGGAGGTAGAA-3' and 5'-ACAGCACTCACCAAACCAGAAG-3', respectively. Samples were run in triplicate using TaKaRa SYBR Premix $^{\odot}$ Ex Taq $^{\text {Tn }}$ II (Tli RNaseH Plus). Glyceraldehyde3-phosphate dehydrogenase (GAPDH) was assayed simultaneously by qRT-PCR as an endogenous invariant control. Relative differences in mRNA expression level between AS patients and healthy controls were determined using the $\Delta \Delta C_{t}$ method as described previously [19].

\section{Results}

\section{Identifying differentially methylated loci}

Pearson correlation analysis results for methylation $\beta$ values of all study subjects are presented in Additional file 1: Figure S1. Additional file 2: Figure S2 shows the two-way hierarchical cluster analysis results for genomewide methylation profiles.

A total of 473,685 CpG sites passing the quality control procedure were analyzed in this study. Compared with healthy controls, we detected 1915 differentially methylated CpGs, including 1611 hypermethylated loci and 304 hypomethylated loci, in AS PBMCs. The 1915 differentially methylated loci were mapped to 1214 genes, including 1045 hypermethylated genes and 169 hypomethylated genes (Additional file 3: Table S1). Across the whole genome, the CpG locus cg14323910 located on the $H L A-D Q B 1$ gene was the most significant for AS (adjusted $P=1.84 \times 10^{-6}, \beta$ difference = 0.5634). Additionally, the cg04777551 locus of HLA$D Q B 1$ presented a suggestive association with AS (adjusted $P=1.46 \times 10^{-3}, \beta$ difference $=0.3594$ ).

\section{GO and pathway enrichment analysis}

We identified four GO terms significantly enriched in the differentially methylated genes, functionally related to antigen dynamics and function (Table 2). As presented in Table 3, pathway enrichment analysis detected 10 significant pathways for AS, such as antigen processing and presentation $\left(P=1.76 \times 10^{-3}\right)$, intestinal immune 
Table 2 GO enrichment analysis results of differentially methylated genes between AS patients and healthy controls

\begin{tabular}{|c|c|c|c|}
\hline GO ID & Description & Genes & $P$ value \\
\hline GO:0002504 & $\begin{array}{l}\text { Antigen processing and presentation of peptide } \\
\text { or polysaccharide antigen via MHC class II }\end{array}$ & $\begin{array}{l}\text { HLA-DMB, HLA-DOA, HLA-DOB, HLA-DPB1, HLA-DQA1, } \\
\text { HLA-DQB1 }\end{array}$ & $1.11 \times 10^{-5}$ \\
\hline GO:0042605 & Peptide antigen binding & $\begin{array}{l}\text { DHCR24, HLA-A, HLA-B, HLA-C, HLA-DQB1, HLA-DRB1, } \\
\text { HLA-H, MAML1, SLC7A5 }\end{array}$ & $5.14 \times 10^{-6}$ \\
\hline GO:0042613 & MHC class II protein complex & $\begin{array}{l}\text { HLA-DMB, HLA-DOA, HLA-DOB, HLA-DPB1, HLA-DQA1, } \\
\text { HLA-DQB1, HLA-DRB1 }\end{array}$ & $7.97 \times 10^{-6}$ \\
\hline GO:0071556 & $\begin{array}{l}\text { Integral to lumenal side of endoplasmic } \\
\text { reticulum membrane }\end{array}$ & $\begin{array}{l}\text { CALR, HLA-A, HLA-B, HLA-C, HLA-DPB1, HLA-DQA1, } \\
\text { HLA-DQB1, HLA-DRB1 }\end{array}$ & $8.79 \times 10^{-5}$ \\
\hline
\end{tabular}

GO Gene Ontology, AS ankylosing spondylitis

network for IgA production $\left(P=1.94 \times 10^{-4}\right)$, and autoimmune thyroid disease $\left(P=3.93 \times 10^{-5}\right)$.

\section{qRT-PCR validation}

To further assess the functional relevance of the identified $H L A-D Q B 1$ gene for AS, we compared the mRNA expression levels of $H L A-D Q B 1$ in PBMCs between five AS patients and five healthy controls. The mRNA expression level of $H L A-D Q B 1$ in AS patients was significantly lower than that in healthy controls. The average expression ratio of $H L A-D Q B 1$ was $0.48 \pm 0.10($ mean $\pm \mathrm{SD})(P<0.001)$.

\section{Discussion}

In this study, we observed a significant difference in DNA methylation profiles of PBMCs between AS patients and healthy control subjects, suggesting the implication of methylation in the development of AS. We also identified the significantly hypermethylated $H L A-D Q B 1$ gene in AS PBMCs. qRT-PCR further observed significant downregulation of $H L A-D Q B 1$ mRNA in AS PBMCs compared with healthy controls, supporting the functional relevance of $H L A-D Q B 1$ for AS.

One of the important findings of this study is that the $H L A-D Q B 1$ gene is involved in the development of AS. Human leukocyte antigen (HLA) genes are highly polymorphic gene clusters responsible for the regulation of the immune system in humans [20-24]. HLA-DQB1 belongs to the HLA class II molecules, which are involved in activating immune responses and recognizing self or foreign antigens [25]. HLA-DQB1 plays a central role in the immune system by presenting peptides derived from extracellular proteins [26]. The highly polymorphic amino acid chains of DQB1 are capable of forming the peptide binding groove that presents antigen to $\mathrm{CD} 4^{+} \mathrm{T}$ helper cells [27], and controlling the immune response $[28,29]$. Previous studies reported that $H L A-D Q B 1$ was associated with radiographic severity in AS [30,31]. The different alleles of $H L A-D Q B 1$ were also associated with the age of AS onset [31]. In addition, $H L A-D Q B 1$ was closely associated with multiple autoimmune-related diseases [28, 29], such as multiple sclerosis [28] and type I diabetes [32]. Based on previous and present study results, it is reasonable to infer that the aberrant expression of $H L A-D Q B 1$ due to DNA hypermethylation contributed to the development of AS. Further biological studies are warranted to confirm our findings and clarify the potential mechanism of $H L A-D Q B 1$ involved in the pathogenesis of AS.

We found that the identified differentially methylated regions tended to be located in the genes functionally related to immune-related dynamics and function. The $\mathrm{GO}$ and pathway enrichment analysis of differentially

Table $3 \mathrm{KEGG}$ pathway enrichment analysis results of differentially methylated genes between AS patients and healthy controls

\begin{tabular}{llll}
\hline KEGG ID & Description & DMG & $P$ value \\
\hline hsa05332 & Graft-versus-host disease & 11 & $2.31 \times 10^{-5}$ \\
hsa05320 & Autoimmune thyroid disease & 11 & $3.93 \times 10^{-5}$ \\
hsa04940 & Type I diabetes mellitus & 11 & $5.05 \times 10^{-5}$ \\
hsa05310 & Asthma & 9 & $5.19 \times 10^{-5}$ \\
hsa05330 & Allograft rejection & 10 & $6.19 \times 10^{-5}$ \\
hsa04672 & Intestinal immune network for lgA production & 11 & $1.94 \times 10^{-4}$ \\
hsa04920 & Adipocytokine signaling pathway & 13 & $4.47 \times 10^{-4}$ \\
hsa04514 & Cell adhesion molecules & 19 & $19.84 \times 10^{-4}$ \\
hsa04612 & Antigen processing and presentation & 12 & $1.76 \times 10^{-3}$ \\
hsa05416 & Viral myocarditis & 12 & $1.76 \times 10^{-3}$ \\
\hline
\end{tabular}

AS ankylosing spondylitis, KEGG Kyoto Encyclopedia of Genes and Genomes, DMG differentially methylated genes 
methylated genes further revealed connections between the differentially methylated regions and the enrichment of immune-related genes. For instance, both GO and pathway enrichment analysis results support the implication of dysfunction of antigen processing and presentation (hsa04920) in the development of AS. Antigen processing and presentation is mainly mediated by HLA class I molecules. Zhu et al. [33] found that antigen processing and presentation is significantly associated with AS. As a high polymorphic member of HLA class I molecules, the important role of HLA-B27 in the pathogenesis of AS has been well documented. Briefly, HLA$B 27$ binds unique peptides of microbial or self-origin (antigen) and presents them to $\mathrm{CD}^{+} \mathrm{T}$ cells. Large multifunctional proteases and transporters associated with antigen presentation act as chaperones for peptide transport. Antigen peptides generated by proteasomal degradation can be further subjected to amino peptidase-mediated trimming before reaching the optimal size for HLA class I binding $[34,35]$. The $H L A-C$ of HLA class I molecules has also been confirmed to be associated with AS [36]. More interestingly, we found that the intestinal immune network for IgA production pathway (hsa04672), the autoimmune thyroid disease pathway (hsa05320), and the asthma pathway (hsa05310) were associated with AS in this study. Previous studies have observed the coexistence of abnormal IgA levels and AS [37, 38]. Compared with general populations, higher prevalence of autoimmune thyroid disease and asthma in AS patients have been reported by previous studies $[39,40]$.

There were some limitations in this study. First, we used five AS patients and five healthy controls as the study samples for DNA methylation profiling. This was a relatively small sample, which may lead to loss of statistical power caused by potential selection bias. Using another independent sample of five AS patients and five healthy controls, qRT-PCR was conducted to validate the functional relevance of the hypermethylated $H L A-D Q B 1$ gene with AS. qRT-PCR observed significant downregulation of $H L A-D Q B 1$ in AS patients, supporting the accuracy of the DNA methylation profile analysis results. Further biological studies are warranted to confirm our findings and clarify the molecular mechanism of $H L A-D Q B 1$ involved in the development of AS. Second, it should be noted that AS patients usually underwent NSAID treatments. Because of the need for clinical AS treatments, it is difficult to exclude the possible impact of NSAIDs on DNA methylation in this study. Further biological studies are warranted to confirm our findings.

\section{Conclusions}

We conducted a genome-wide DNA methylation profile comparative study and observed significant difference in
DNA methylation profiles between AS patients and healthy subjects. We also reported a set of differentially methylated genes and identified $H L A-D Q B 1$ involved in the development of AS. This study provides novel clues for clarifying the genetic mechanism as well as identifying biomarkers for AS.

\section{Additional files}

Additional file 1: Figure S1. Showing Pearson correlation coefficient plot of the genome-wide DNA methylation study results. $X$ axis, average $\beta$ values in cases; $Y$ axis, average $\beta$ values in controls. (JPEG $104 \mathrm{~kb}$ )

Additional file 2: Figure S2. Showing two-way hierarchical cluster analysis results of study samples and DNA methylation profiles. (JPEG 1170 kb)

Additional file 3: Table S1. Presenting significantly differentially methylated CPG sites between AS patients and healthy controls. (XLSX $167 \mathrm{~kb}$ )

Additional file 4: Presents genome-wide DNA methylation microarray data. (CSV $244140 \mathrm{~kb}$ )

Abbreviations

AS: Ankylosing spondylitis; FDR: False discovery rate; GO: Gene Ontology; PBMC: Peripheral blood mononuclear cell; PBS: Phosphate-buffered saline; qRT-PCR: Quantitative real-time reverse transcription-polymerase chain reaction

\section{Acknowledgements}

Not applicable.

\section{Funding}

The study was supported by National Natural Scientific Fund of China (81472925, 81673112), the Technology Research and Development Program of in Shaanxi Province of China (2013KJXX-51), and the Fundamental Research Funds for the Central Universities.

Availability of data and materials

The genome-wide DNA methylation microarray data will be submitted to ArrayExpress (Additional file 4)

\section{Authors' contributions}

FZ takes responsibility for the integrity of the work as a whole, from inception to the finished manuscript. FZ and $X G$ were responsible for conception and design. JCH, YL, JWX, YW, and AWH were responsible for collection and analysis of data. JCH, WYW, and FZ were responsible for interpretation of the data. JCH, YL, JWX, YW, WYW, AWH, QRF, XG, and FZ were responsible for drafting, revising and final approval of the manuscript.

\section{Authors' information}

Not applicable.

Ethics approval and consent to participate

This study was approved by the Institutional Review Board of Xi'an Jiaotong University. Written informed consents were obtained from all study subjects.

\section{Consent for publication}

This study has obtained consent to publish from the participant (or legal parent or guardian for children) to report individual patient data.

\section{Competing interests}

The authors declare that they have no competing interests.

\section{Publisher's Note}

Springer Nature remains neutral with regard to jurisdictional claims in published maps and institutional affiliations. 


\section{Author details}

"Key Laboratory of Trace Elements and Endemc Diseases of National Health and Family Planning Commission, School of Public Health, Health Science Center, Xi'an Jiaotong University, Xi'an, People's Republic of China. ${ }^{2}$ Xi'an No.5 Hospital, Xi'an, People's Republic of China. ${ }^{3}$ Department of Clinical Medicine, Health Science Center, Xi'an Jiaotong University, Xi'an, People's Republic of China.

\section{Received: 16 January 2017 Accepted: 6 July 2017}

Published online: 25 July 2017

\section{References}

1. Seregin SS, Rastall DP, Evnouchidou I, Aylsworth CF, Quiroga D, Kamal RP, Godbehere-Roosa S, Blum CF, York IA, Stratikos E, et al. Endoplasmic reticulum aminopeptidase-1 alleles associated with increased risk of ankylosing spondylitis reduce HLA-B27 mediated presentation of multiple antigens. Autoimmunity. 2013;46(8):497-508.

2. Schett $\mathrm{G}$. Bone formation versus bone resorption in ankylosing spondylitis. Adv Exp Med Biol. 2009:649:114-21.

3. El Tecle NE, Abode-lyamah KO, Hitchon PW, Dahdaleh NS. Management of spinal fractures in patients with ankylosing spondylitis. Clin Neurol Neurosurg. 2015;139:177-82.

4. Feldtkeller E, Khan MA, van der Heijde D, van der Linden S, Braun J. Age at disease onset and diagnosis delay in HLA-B27 negative vs. positive patients with ankylosing spondylitis. Rheumatol Int. 2003;23(2):61-6.

5. Braun J, Bollow M, Remlinger G, Eggens U, Rudwaleit M, Distler A, Sieper J. Prevalence of spondylarthropathies in HLA-B27 positive and negative blood donors. Arthritis Rheum. 1998;41(1):58-67.

6. Reveille JD. The genetic basis of ankylosing spondylitis. Curr Opin Rheumatol. 2006;18(4):332-41.

7. Brown MA, Kennedy LG, MacGregor AJ, Darke C, Duncan E, Shatford JL, Taylor A, Calin A, Wordsworth P. Susceptibility to ankylosing spondylitis in twins: the role of genes, HLA, and the environment. Arthritis Rheum. 1997;40(10):1823-8.

8. Hamersma J, Cardon LR, Bradbury L, Brophy S, van der Horst-Bruinsma I, Calin A, Brown MA. Is disease severity in ankylosing spondylitis genetically determined? Arthritis Rheum. 2001:44(6):1396-400.

9. Brophy S, Hickey S, Menon A, Taylor G, Bradbury L, Hamersma J, Brown M, Calin A. Concordance of disease severity among family members with ankylosing spondylitis? J Rheumatol. 2004;31(9):1775-8.

10. Wright PB, McEntegart A, McCarey D, Mclnnes IB, Siebert S, Milling SW. Ankylosing spondylitis patients display altered dendritic cell and $T$ cell populations that implicate pathogenic roles for the IL-23 cytokine axis and intestinal inflammation. Rheumatology (Oxford). 2016;55(1):120-32.

11. Levin $\mathrm{HL}$, Moran JV. Dynamic interactions between transposable elements and their hosts. Nat Rev Genet. 2011;12(9):615-27.

12. Jaenisch $\mathrm{R}$, Bird A. Epigenetic regulation of gene expression: how the genome integrates intrinsic and environmental signals. Nat Genet. 2003:33(Suppl):245-54.

13. Peters J. The role of genomic imprinting in biology and disease: an expanding view. Nat Rev Genet. 2014;15(8):517-30.

14. Glossop JR, Emes RD, Nixon NB, Haworth KE, Packham JC, Dawes PT, Fryer AA, Mattey DL, Farrell WE. Genome-wide DNA methylation profiling in rheumatoid arthritis identifies disease-associated methylation changes that are distinct to individual T- and B-lymphocyte populations. Epigenetics. 2014;9(9):1228-37.

15. de la Rica L, Urquiza JM, Gomez-Cabrero D, Islam AB, Lopez-Bigas N, Tegner J, Toes RE, Ballestar E. Identification of novel markers in rheumatoid arthritis through integrated analysis of DNA methylation and microRNA expression. J Autoimmun. 2013:41:6-16.

16. Aslani S, Mahmoudi M, Garshasbi M, Jamshidi AR, Karami J, Nicknam MH. Evaluation of DNMT1 gene expression profile and methylation of its promoter region in patients with ankylosing spondylitis. Clin Rheumatol. 2016;35(11):2723-31.

17. Lai NS, Chou JL, Chen GCW, Liu SQ, Lu MC, Chan MWY. Association between cytokines and methylation of SOCS-1 in serum of patients with ankylosing spondylitis. Mol Biol Rep. 2014;41(6):3773-80.

18. van der Linden S, Valkenburg HA, Cats A. Evaluation of diagnostic criteria for ankylosing spondylitis. A proposal for modification of the New York criteria. Arthritis Rheum. 1984;27(4):361-8.
19. Ciccia F, Rizzo A, Guggino G, Cavazza A, Alessandro R, Maugeri R, Cannizzaro A, Boiardi L, lacopino DG, Salvarani C, et al. Difference in the expression of IL-9 and IL-17 correlates with different histological pattern of vascular wall injury in giant cell arteritis. Rheumatology (Oxford). 2015;54(9):1596-604.

20. Repiska V, Shawkatova I, Bohmer D, Hatzibougias D, Sisovsky V, Danihel L. Gestational choriocarcinoma analyzed by polymerase chain reaction amplification of polymorphic VNTR and human leukocyte antigen regions. Int J Gynaecol Obstet. 2010;110(2):152-4.

21. Andreoni A, Bondani M, Nardo L. Time-resolved FRET method for typing polymorphic alleles of the human leukocyte antigen system by using a single DNA probe. Photochem Photobiol Sci. 2009;8(8):1202-6.

22. Schroeder S, Reck M, Hoeft A, Stuber F. Analysis of two human leukocyte antigen-linked polymorphic heat shock protein 70 genes in patients with severe sepsis. Crit Care Med. 1999;27(7):1265-70.

23. Huang W, Connor E, Rosa TD, Muir A, Schatz D, Silverstein J, Crockett S, She JX, Maclaren NK. Although DR3-DQB1 ${ }^{*} 0201$ may be associated with multiple component diseases of the autoimmune polyglandular syndromes, the human leukocyte antigen DR4-DQB1*0302 haplotype is implicated only in beta-cell autoimmunity. J Clin Endocrinol Metab. 1996;81(7):2559-63.

24. Huh KB, Lee HC, Kim HM, Lee HR, Hong CS, Lee SY, Choi HJ, Park K, Kim CK. Human leukocyte antigen (HLA) in Korean patients with autoimmune thyroid diseases. Korean J Intern Med. 1986;1 (2):243-8.

25. Luppi P, Licata A, Haluszczak C, Rudert WA, Trucco G, McGowan Jr FX Finegold D, Boyle GJ, Trucco M. Analysis of TCR Vbeta repertoire and cytokine gene expression in patients with idiopathic dilated cardiomyopathy. J Autoimmun. 2001;16(1):3-13.

26. Veijola R, Reijonen $H$, Vahasalo P, Sabbah E, Kulmala P, Ilonen J, Akerblom HK, Knip M. HLA-DQB1-defined genetic susceptibility, beta cell autoimmunity, and metabolic characteristics in familial and nonfamilial insulin-dependent diabetes mellitus. Childhood Diabetes in Finland (DiMe) Study Group. J Clin Invest. 1996;98(11):2489-95.

27. Watts $C$. The exogenous pathway for antigen presentation on major histocompatibility complex class II and CD1 molecules. Nat Immunol. 2004:5(7):685-92.

28. Kollaee A, Ghaffarpor M, Ghlichnia HA, Ghaffari SH, Zamani M. The influence of the HLA-DRB1 and HLA-DQB1 allele heterogeneity on disease risk and severity in Iranian patients with multiple sclerosis. Int J Immunogenet. 2012;39(5):414-22

29. Gashimova AD, Sokolov Al, Nikol'skaia GV, Gapparov MM. Changes in lipid metabolism and renewal of sialic acids in the composition of glycoproteins of adipose tissue during carbohydrate loading. Vopr Med Khim. 1989;35(1):114-8.

30. Ward MM, Hendrey MR, Malley JD, Learch TJ, Davis Jr JC, Reveille JD, Weisman $\mathrm{MH}$. Clinical and immunogenetic prognostic factors for radiographic severity in ankylosing spondylitis. Arthritis Rheum. 2009;61(7):859-66

31. Pimentel-Santos FM, Matos M, Ligeiro D, Mourao AF, Ribeiro C, Costa J, Santos H, Barcelos A, Pinto P, Cruz M, et al. HLA alleles and HLA-B27 haplotypes associated with susceptibility and severity of ankylosing spondylitis in a Portuguese population. Tissue Antigens. 2013;82(6):374-9.

32. Beretta L, Rueda B, Marchini M, Santaniello A, Simeon CP, Fonollosa V, Caronni M, Rios-Fernandez R, Carreira P, Rodriguez-Rodriguez L, et al. Analysis of class II human leucocyte antigens in Italian and Spanish systemic sclerosis. Rheumatology (Oxford). 2012;51(1):52-9.

33. Zhu ZQ, Tang JS, Cao XJ. Transcriptome network analysis reveals potential candidate genes for ankylosing spondylitis. Eur Rev Med Pharmacol Sci. 2013;17(23):3178-85.

34. Kim TH, Uhm WS, Inman RD. Pathogenesis of ankylosing spondylitis and reactive arthritis. Curr Opin Rheumatol. 2005;17(4):400-5.

35. Chou CT. Factors affecting the pathogenesis of ankylosing spondylitis. Chin Med J. 2001;114(2):211-2.

36. Kim K, Bang SY, Lee S, Lee HS, Shim SC, Kang YM, Suh CH, Sun C, Nath SK, Bae SC, et al. An HLA-C amino-acid variant in addition to HLA-B*27 confers risk for ankylosing spondylitis in the Korean population. Arthritis Res Ther. 2015;17:342.

37. Zambrano-Zaragoza JF, de Jesus Duran-Avelar M, Rodriguez-Ocampo AN, Garcia-Latorre E, Burgos-Vargas R, Dominguez-Lopez ML, Pena-Virgen S, Vibanco-Perez N. The 30-kDa band from Salmonella typhimurium: IgM, IgA and IgG antibody response in patients with ankylosing spondylitis. Rheumatology (Oxford). 2009;48(7):748-54. 
38. Stergiouli I, Tsifetaki N, Voulgari PV, Kosta P, Argyropoulou MI, Drosos AA. Ankylosing spondylitis and IgA deficiency. Joint Bone Spine. 2009;76(1):110-1.

39. Emmungil H, Erdogan M, Kalfa M, Karabulut G, Kocanaogullari H, Inal V, Aksu K, Oksel F, Kabasakal Y, Keser G. Autoimmune thyroid disease in ankylosing spondylitis. Clin Rheumatol. 2014;33(7):955-61.

40. Shen TC, Lin CL, Wei CC, Chen CH, Tu CY, Hsia TC, Shih CM, Hsu WH, Sung

FC. The risk of asthma in patients with ankylosing spondylitis: a populationbased cohort study. PLoS One. 2015;10(2):e0116608.

Submit your next manuscript to BioMed Central and we will help you at every step:

- We accept pre-submission inquiries

- Our selector tool helps you to find the most relevant journal

- We provide round the clock customer support

- Convenient online submission

- Thorough peer review

- Inclusion in PubMed and all major indexing services

- Maximum visibility for your research

Submit your manuscript at www.biomedcentral.com/submit 